\title{
Making sense of corruption studies: an introduction
}

\section{Alina Mungiu-Pippidi and Paul M. Heywood}

The study of corruption can best be conceptualized as an archipelago resulting from several streams flowing into the sea, with different degrees of prior communication through the channels of their tributaries. As the tide comes in, some common knowledge is left deposited across the most exposed areas by the returning sea: but others, further upstream, remain fairly isolated. Alongside some recently achieved coherence that this introduction and this book have had to struggle to find, a myriad of separate understandings exist, which do not share even a basic language. To do justice to such diversity is therefore impossible. Regardless of how wellintentioned, any collection that seeks to review the vast array of studies of corruption is bound to show some partiality. Choices need to be made: our first choice is to find sufficient commonalities across disciplines and approaches when it comes to concepts, methods and policies used in the empirical study of corruption, while still canvassing as many types as possible. We express regret for the many research areas and authors that we had to leave out in pursuing our choice of what the current state of the art in corruption research has to offer.

On top of the desideratum of consistency across disciplines, we introduce a second desideratum, that of actionability, which informs many of the choices of topics in this volume. Corruption has always been a key concept in the science of government. Starting with Plato and Aristotle, students of government have conceived 'good' government as reflecting the universal welfare of the polity (as defined by the citizenry) versus the partial interest of the ruler and his clique (Mulgan 2012). The Renaissance and then the Enlightenment also promoted their own visions of good government/governance, a commitment later encompassed in formal documents that range from the 1879 Declaration of the Rights of Man and of the Citizen to the 2004 United Nations Convention against Corruption. From the nineteenth century, historical sociology also started to study patterns of social allocation and their connection with power: Max Weber, a post-Marxist scholar, outlined the fundamental notions for the understanding of corruption, in particular through the ideas of patrimonialism and bureaucracy. Twentiethcentury political development scholars and sociologists have further advanced this approach. Anthropologists and social psychologists have also brought essential contributions to our understanding of political development through concepts such as reciprocity, gift-making, conformity and social capital. Economists became interested in corruption relatively later, as both Marxists and Liberals have long 
conceived the state in opposite ways, but equally isolated from the interests of people in government.

This changed only with the emergence of the public choice school. A 1967 paper by Gordon Tullock focusing on the United States forecast high social costs for an economy of privilege versus a free market, since seeking a monopoly would imply a wasteful investment of resources (Tullock 1967). Tullock and Buchanan also introduced the distinction between profit-seeking and rent-seeking, with the former based on merit (providing a product or service that consumers would be willing to pay more for than the opportunity cost of the resources used) and the latter based on coercion by preventing others from competing equally or by forcibly taking their wealth (Buchanan et al. 1980). Unlike profit-seeking by market means, rent-seeking by political means doesn't create wealth; it merely transfers privilege from one party to another and wastes the resources used to secure rents, because these are invested to produce an outcome in which nothing of value is created. Furthermore, acquiring rents through political power distorts the operation of market processes, affecting interest rates and the prices of goods and services, thereby actually destroying wealth (Buchanan et al. 1980). Rent-seeking itself is a concept coined by the economist Anne Krueger (1974) to indicate the situation when firms compete for privileges from the authorities (for instance, import licences) rather than in a free market.

The 1990 saw the development of fully-fledged theories from economists, giving corruption a central role in explaining development and instituting what is known as the primacy of politics argument. Nobel prize-winning economist, Douglass North, advanced the preliminaries of a grand corruption theory, arguing that 'as human beings became increasingly interdependent, and more complex institutional structures were necessary to capture the potential gains from trade', societies needed to 'develop institutions that will permit anonymous, impersonal exchange across time and space'; however, their success in creating the right institutions varied due to diverse 'local experience' (North 1993, p. 4). Societies that do not manage to create open access and impersonal, merit-based systems to govern both the market and the state-citizen relationship remain poor. Their economy remains one of privileged rents, and their state remains captured by particular interests, unable to evolve towards autonomy and the production of public goods in sufficient quantity.

The economist Daron Acemoglu (1995) developed on similar theoretical foundations an equilibrium model of the allocation of talent between productive and unproductive activities, arguing that allocations of past generations, as well as expectations of future allocations, influence current rewards and a society may get trapped in a rent-seeking steady state equilibrium. Even if competition exists in such a society both in politics and in the economy, the main stake of politics amounts to the spoiling public resources for the benefit of particular groups, regardless of whether competitive elections exist (Mungiu 2006). 
The concept of corruption control as some form as equilibrium also informs much of the World Bank literature based on the Worldwide Governance Indicators, which show the close linkage between regulatory quality, government effectiveness, rule of law, voice and accountability, and control of corruption (Huther and Shah 2000). Two recent works explicitly build on the equilibrium notion first and most famously introduced by economist Gary Becker (1968): Mungiu-Pippidi (2015b) depicts a model of corruption control as the institutional equilibrium between resources for and constraints on corruption, while Fisman and Golden (2017) describe corruption as an equilibrium resulting from 'mutual expectations'.

This approach to corruption as an institution needs important qualifications if it is to cross disciplines. The followers of Douglass North define institutions as 'rules of the game' and therefore distinct from 'organizations', which are frequently called 'institutions' by political theorists and those in other social sciences (for a detailed discussion, see Hodgson 2006). 'Institutions' in institutional economics are both formal (such as constitutions) and informal (such as gift-giving to officials), making governance a complex set of interactions between formal and informal ones, which determine who gets what. Political scientists sometimes define as 'institutionalists' not this group of political and development economists (which also includes Matt Andrews, Lant Pritchett, Barry Weingast, Paul Collier, Mushtaq Khan and many others), but a quite distinct group within their discipline who argue that the formal political institutions (such as electoral systems or other constitutional arrangements) shape governance. Chapter 5 in this book by Mares and Young offers a review of this literature in relation to electoral corruption.

Finally, an alternative understanding of institutional corruption - isolated from any broad schools of thought as described above - comes from Dennis Thompson (2018) and his followers, prompted by a US corruption scandal and more generally the attempt to argue that undue 'institutional corruption' in a democracy occurs 'when individuals within the institution become dependent upon an influence that distracts them from the intended purpose of that institution' (Lessig 2011, p. 15). The institution's intended (constitutional) purpose thus needs to be specified to diagnose its 'corruption'. Clearly, Thompson's 'institutions' are North's 'organisations', underlining that scholars of corruption, as in Oscar Wilde's aphorism, can remain divided by a common language.

So, while this volume does seek to identify some coherence across disciplines, tensions or sheer lack of communication and reciprocal understanding should not be downplayed. Golden and Mahdavi (2015) describe three separate tensions in the literature on corruption. First, they find some tension between studies that use cross-national data and those that use subnational data, with divergent results emerging even with similar research questions. An example in this book is the new literature on corruption at grassroots level in relation to social norms, which struggles to isolate corruption attitudes from broader normative contexts. Second, some tension emerges between studies that use observational data, on the one hand, and those that employ experimental or quasi-experimental research methods 
on the other - a tension that characterizes more than just corruption studies. In corruption studies, experimental research which does not control for national context invariably fails in the principal-agent paradigm, as remarked by Persson et al. (2013), as it focuses on the motivations and incentives of agents. We know, however, that those matter only in contexts where agents have reached a point of having actual autonomy from their 'principals', the rulers: in other words, where an autonomous bureaucracy exists already and corruption is an exception and not the rule (Mungiu 2006; Gächter and Schulz 2016). Such studies should therefore be contextualized: where the rule of the game is government based on partiality (particularism), the individual motivations of an agent are hardly relevant. The principal-agent paradigm should therefore be restricted to certain contexts only. Third, Golden and Mahdavi find a tension between formal institutional and noninstitutional explanations of corruption. An abundance of literature deals with the effect of constitutional factors on governance. Many development agents seem to believe that the introduction of formal institutions will be automatically followed by a change in norms and practices. Hence, the promotion of anti-corruption of the last two decades has also resulted in the largest implementation gap in history between formal and informal institutions of governance. A recent summary of evidence exists in the 2017 special issue of the journal Crime, Law and Social Change, edited by Mungiu-Pippidi (2017a). Some of the evidence is revisited in this collection in Chapter 10 by Kukutschka.

The plan of this book, therefore, is as follows. The first part, 'Concepts and approaches', includes, alongside this very brief review of concepts, a further three chapters. Mungiu-Pippidi and Fazekas (Chapter 2) provide an appraisal of advances in the measurement of corruption, laying emphasis on the purposes of studying corruption, the importance of developing actionable measures and how to identify appropriate indicators. In turn, Heywood (Chapter 3) analyses how the meanings and modalities of political corruption in contemporary research have changed and developed in line with broader socio-economic developments in a more interdependent world. Finally, a review of recent approaches to the study of social norms and corruption, by Köbis, Jackson and Iragorri Carter (Chapter 4), explores how recent empirical research aligns with the literature on injunctive and descriptive social norms as drivers of practice.

In the second part, 'Varieties and connotations', Mares and Young (Chapter 5) offer a detailed analysis of how electoral clientelism varies both in type and strategy across regions, countries and individuals. In Chapter 6 on gender and corruption, Merkle highlights innovative new research on gendered forms of corruption and the role of gender norms. Then, Erlingsson and Kristinsson (Chapter 7) examine how the Nordic countries' reputation for being low-corrupt becomes more complicated when factoring in citizens' perceptions and more hidden forms of corruption. Chapter 8 by Berti, Bratu and Wickberg critically reviews research on the relationship between the media and corruption, laying emphasis on issues of freedom and control, on one side, as well as the social construction of the concept, on the other. In Chapter 9, Kubbe and Loli close this section by exploring the links between 
corruption and populism, emphasising the respective role of individuals and institutions and the importance of trust and emotion.

In the third and final part of the volume, 'The anti-corruption repertory', Kukutschka (Chapter 10) argues that lack of success in combating corruption reflects a tension between the respective roles of market-based and legal approaches to tackling the issue. In Chapter 11, Kossow focuses on the role and promise of information and communication technology in developing anti-corruption tools, identifying key gaps in the research so far. Finally, in Chapter 12, Bocchiola, Ceva and Vinciguerra, address the most popular anti-corruption tool, whistleblowing, looking at current definitional debates and approaches before assessing its role and impact on curbing corruption and promoting good governance.

To do justice to such a fast-developing area as corruption, further volumes could be added to this one. Corruption as policy failure in sectors such as public health or education, corruption and inequality, or corruption and business ethics are areas of increasing attention from scholars but are barely touched in this collection of essays. The 'instrumentalization' of anti-corruption and other approaches stemming from deconstructivism are also worth mentioning: Le Monde Diplomatique dedicated a whole issue to them in 2019, as the ascension of anti-corruption opened new avenues of contestation and manipulation. In particular, the new global antielite rage and the populist parties riding it have raised corruption high on the political agenda everywhere. The debate on corruption is here to stay: and therefore our understanding needs to progress, too. 